macrophages, bone marrow-derived mast cells and articular chondrocytes. The first three were co-cultured with articular chondrocytes separately. LHVS, a specific inhibitor of cathepsin S, and E64, a broad-spectrum inhibitor of cysteine protease, were added into the cocultures of macrophages and articular chondrocytes separately. Also, C48/80, an activator of mast cells, LHVS, and E64 were added into the cocultures of mast cells and articular chondrocytes separately. The culture supernatant fluid was collected. The concentration of cathepsin S and type II collagen were measured by ELISA. The expression of type II collagen mRNA in each group was detected with RTPCR.

Results: Macrophages and mast cells expressed cathepsin S, while synovial fibroblasts did not express cathepsin S. Synovial fibroblasts had little effect on the expression of type II collagen from articular chondrocytes. When articular chondrocytes were co-cultured with macrophages, the expression of type II collagen decreased $(8.79 \pm 2.79 \mathrm{ng} / \mathrm{ml})$, compared with the control group $(17.75 \pm 7.84 \mathrm{ng} / \mathrm{ml})$. The secretion of type II collagen could return to normal by the inhibitors of cathepsin S, both LHVS $(16.15 \pm 8.05 \mathrm{ng} / \mathrm{ml})$ and E64 $(12.55 \pm 6.64$ $\mathrm{ng} / \mathrm{ml}$ ). When articular chondrocytes were co-cultured with mast cells, the type II collagen could be restrained by C48/80 $(9.82 \pm 0.42 \mathrm{ng} / \mathrm{ml})$, compared with the control group $(26.09 \pm 9.34 \mathrm{ng} / \mathrm{ml})$. Similarly, the secretion of type II collagen could return to normal by LHVS and E64 $(16.15 \pm 8.05 \mathrm{ng} / \mathrm{ml}, 12.55 \pm 6.64 \mathrm{ng} / \mathrm{ml}$, respectively). There was no significant difference in the expression of type II collagen mRNA between different groups. It showed that the type II collagen was not suppressed at the transcription level, but was mainly destroyed by cathepsin $S$ after secretion.

Conclusions: Macrophages and mast cells are the major sources of cathepsin $\mathrm{S}$, which might be the main factor that destroys type II collagen secreted from articular chondrocytes in RA mice.

Disclosure of Interest: None declared

DOI: 10.1136/annrheumdis-2017-eular.5664

\section{FRI0051 EARLY ARTHRITIS INDUCES DISTURBANCES AT BONE NANOSTRUCTURAL LEVEL REFLECTED IN DECREASED TISSUE HARDNESS}

B. Vidal ${ }^{1}$, R. Cascão ${ }^{1}$, M. Finnilä ${ }^{2,3}$, I. Lopes ${ }^{1}$, S. Saarakkala ${ }^{2,4,5}$, P. Zioupos ${ }^{6}$, H. Canhão ${ }^{7}$, J. Fonseca ${ }^{1,8}{ }^{1}$ Instituto de Medicina Molecular, Faculdade de Medicina, Universidade de Lisboa, Lisboa, Portugal; ${ }^{2}$ Research Unit of Medical Imaging, Physics and Technology, Faculty of Medicine, University of Oulu, Oulo; ${ }^{3}$ Department of Applied Physics, University of Eastern Finland, Kuopio; ${ }^{4}$ Medical Research Center Oulo, Oulu University; ${ }^{5}$ Department of Diagnostic Radiology, Oulu University Hospital, Oulo, Finland; ${ }^{6}$ Biomechanics Labs, Cranfield Forensic Institute, Cranfield University, Swindon, United Kingdom; ${ }^{7}$ EpiDoC Unit, CEDOC, NOVA Medical School, NOVA University; ${ }^{8}$ Rheumatology Department, Centro Hospitalar de Lisboa Norte, EPE, Hospital de Santa Maria, Lisbon Academic Medical Centre, Lisboa, Portugal

Background: Arthritis induces joint erosions and skeletal bone fragility. Objectives: The main goal of this work was to analyze the early arthritis induced events at bone tissue level.

Methods: Eighty-eight Wistar rats were randomly housed in experimental groups, as follows: adjuvant induced arthritis $(\mathrm{N}=47)$ and a control healthy group $(\mathrm{N}=41)$. Rats were monitored during 22 days for the inflammatory score, ankle perimeter and body weight and sacrificed at different time points (11 and 22 days post disease induction). Bone samples were collected for histology, micro-CT, 3-point bending, nanoindentation and Fourier transformed infrared spectroscopy (FTIR) analysis. Blood samples were also collected for bone turnover markers and systemic cytokine quantification.

Results: At bone tissue level, measured by FTIR analysis and nanoindentation, there was a reduction of the mineral and collagen content and of hardness in the arthritic group, associated with an increase of the ratio of bone concentric to parallel lamellae and of the area of the osteocyte lacuna. In addition, increased bone turnover and changes in the microstructure and mechanical properties were observed in arthritic animals, since the early phase of arthritis, when compared with healthy controls.

Conclusions: Arthritis induces very early changes at bone tissue level characterized by decreased tissue hardness and of collagen and mineral content. These observations highlight the pertinence of immediate control of inflammation in the initial stages of arthritis.

Disclosure of Interest: None declared

DOI: 10.1136/annrheumdis-2017-eular.3509

\section{FRI0052 SALIVARY PEPTIDYL-ARGININE DEIMINASE AND TANNERELLA FORSYTHIA ARE ASSOCIATED WITH CLINICAL ACTIVITY OF RHEUMATOID ARTHRITIS}

D.-X. Xibillé-Friedmann ${ }^{1}$, J.-I. Martínez-Rivera ${ }^{2}$, M.-A. De la Garza-Ramos ${ }^{3}$, J. González-Christen ${ }^{4}$, S.-M. Carrillo-Vázquez ${ }^{5}$, J.-L. Montiel-Hernandez ${ }^{4}$. ${ }^{1}$ SEIC, Servicios de Salud de Morelos; ${ }^{2}$ CISEI, Instituto Nacional de Salud Pública, Cuernavaca; ${ }^{3}$ CIDICS/Facultad de Odontología, Universidad Autonoma de Nuevo Leon, Monterrey; ${ }^{4}$ Facultad de Farmacia, Universidad Autonoma del Estado de Morelos, Cuernavaca; ${ }^{5}$ Hospital Regional 10. Octubre, ISSSTE, Mexico city, Mexico
Background: Although the expression of bacterial Peptidyl-Arginine Deiminase (PAD) derived from $P$. gingivalis seems critical in explaining the potential effects of severe periodontitis in the development of Rheumatoid arthritis (RA), the association with the presence of the bacteria or anti-P. gingivalis/anti-PPAD antibodies is not always evident suggesting that other bacteria could be involved in the link between oral microbiota and citrullination of host proteins.

Objectives: To confirm the association between RA disease activity in a homogeneous population ( $\mathrm{aCCP}+\mathrm{RA}$ patients), oral PAD activity and the prevalence of other bacterial strains such as $T$. forsythia.

Methods: RA patients fulfilling ACR/EULAR 2010 criteria were evaluated from a periodontal (Periodontal Screening Recoding Index) and rheumatologic standpoint. Patients with Sjögren's syndrome or sicca symptons were excluded. Disease activity was measured using DAS28 (ESR). Oral PAD activity was measured by colorimetric assay and presence of Porphyromonas gingivalis, Tannerella forsythia and Prevotella intermedia was evaluated by PCR. Autoantibody levels were determined by ELISA. Multivariate analysis adjusted for gender, age, time since onset of disease, RF and ESR. Comparisons between groups were performed by Mann-Whitney $U$ testing or Kruskal-Wallis testing per the $t$ variables. Spearman correlation testing was employed to correlate PAD activity and DAS28. Statistical significance was set at $0.05 \%$.

Results: 132 patients were included. After a multivariate analysis an association was observed between severe periodontitis/dental mobility with moderate/high RA disease activity (OR: 4.4 (1.8-14.0), $p=0.04$ and 3.4 (1.1-13.4), $p=0.03$, respectively). Additionally, presence of $P$. gingivalis and $T$. forsythia, but not $P$. intermedia, was significantly associated with moderate/high RA disease activity (3.4 (1.1-10.5), $\mathrm{p}<0.05$ and $4.4(1.2-10.9), \mathrm{p}<0.05)$. Comparing PAD activity in saliva samples of RA patients we found significant differences between the low $(2.3 \pm 0.5)$, moderate $(3.4 \pm 0.8)$ and high $(4.3 \pm 0.3)$ disease activity subgroups $(p<0.01 \%)$, whereas patients in remission demonstrated a PAD activity similar to the low disease activity group $(1.9 \pm 0.39)$. Additionally, we found a significant correlation between oral PAD activity and RA activity, but not with autoantibody titers.

Conclusions: These results show that RA activity is associated with severe periodontitis, high oral PAD activity and the presence of $T$. forsythia and $P$. gingivalis, suggesting that both bacteria equally participate in PAD activity present in the oral microenvironment.

Acknowledgements: Disclosure: This work was supported by a grant from SEP/CONACYT CB-2010 (\#155392).

Disclosure of Interest: None declared

DOI: 10.1136/annrheumdis-2017-eular.3894

\section{FRI0053 ANTIBODIES TO A SUBSET OF CITRULLINATED PEPTIDE ANTIGENS CORRELATE WITH NEUTROPHIL EXTRACELLULAR TRAP LEVELS IN THE SPUTUM OF SUBJECTS AT-RISK FOR FUTURE RA}

K.D. Deane ${ }^{1}$, M. Purmalek ${ }^{2}$, N.L. Seto ${ }^{2}$, E. Bowers ${ }^{1}$, J.M. Norris ${ }^{3}$, V.M. Holers ${ }^{1}$, W. Robinson ${ }^{4}$, M. Kaplan ${ }^{2}$, M.K. Demoruelle ${ }^{1} .{ }^{1}$ Division of Rheumatology, University of Colorado Denver, Aurora; ${ }^{2}$ Systemic Autoimmunity Branch, National Institutes of Health/NIAMS, Bethesda; ${ }^{3}$ Epidemiology, Colorado School of Public Health, Aurora; ${ }^{4}$ Division of Immunology and Rheumatology, Stanford University, Palo Alto, United States

Background: Prior data suggest that anti-citrullinated protein/peptide antibodies (ACPA) may originate in the lung prior to the onset of synovitis in rheumatoid arthritis (RA) (1). Neutrophil extracellular trap (NET) formation is one potential mechanism that could trigger or be associated with local ACPA generation because NETs externalize citrullinated proteins and release peptidylarginine deiminase that could citrullinate nearby proteins (2-4).

Objectives: Using induced sputum, we recently identified a significant correlation between NETs and anti-cyclic citrullinated peptide (CCP) antibodies in subjects at-risk for future RA. Herein, we sought to explore associations of individual ACPAs and NETs in these subjects.

Methods: From the Studies of the Etiology of RA (SERA) cohort, we included 24 RA-free subjects At-Risk for future RA based on familial (i.e. first-degree relative of RA patient) or serologic (i.e. serum anti-CCP positive identified at health fairs) risk. Induced sputum was tested using a bead-based ACPA array for IgG reactivity to 29 individual citrullinated proteins/peptides. Levels of NET complexes in sputum were measured using a deoxyribonucleic acid (DNA)-myeloperoxidase (MPO) and DNA-neutrophil elastase (NE) sandwich ELISA. Analyses included Spearman's correlation and linear regression. Using Bonferonni's correction, results were considered significant if both DNA-MPO and DNA-NE assays had a $\mathrm{p}<0.002$.

Results: Subjects had a median age of 51 years, were $67 \%$ female and $38 \%$ eversmokers. Increasing sputum NET levels significantly correlated with increasing ACPA levels for 27/29 ACPAs, including proteins/peptides of cit-vimentin, citfibrinogen, cit-fibronectin, cit-apoliporoteins and cit-alpha-enolase. After adjusting for ever-smoking, sputum NET levels remained significantly associated with 17/29 ACPAs. The strongest associations ( $p \leq 0.001$ for both NET assays) were cit-H2A/a2 ${ }_{1-20}$, cit-vimentin ${ }_{58-77 \text { cyclic, cit-alpha-enolase }}$ 5-21, cit-fibrinogen ${ }_{27-43}$, cit-fibrinogen $211-230$ cyclic, cit-fibrinogen ${ }_{616-635}$ cyclic, cit-fibrinogen $B_{54-72}$, and citapolipoprotein $\mathrm{E}_{277-269 \text { cyclic. }}$

Conclusions: In subjects At-Risk for future RA, we identified a strong corre- 